\title{
Partial characterization of toxins associated with stem end rot of mango caused by Lasiodiplodia theobromae
}

\section{S. Parthasarathy*, G. Thiribhuvanamala, P. Mohammed Faisal and K. Prabakar}

Department of Plant Pathology, Centre for Plant Protection Studies, Tamil Nadu Agricultural University, Coimbatore 641003 (Tamil Nadu), INDIA

*Corresponding author. E-mail: spsarathyagri@gmail.com

Received: February 9, 2015; Revised received: January 1, 2016; Accepted: April 5, 2016

Abstract: In this study, the toxicity of liquid culture media from different isolates of Lasiodiplodia theobromae was characterized and some properties of the toxic metabolites were distinguished. In this work toxin producing ability of $L$. theobromae was revealed by studying the physical parameters viz., osmotic potential, toxin concentration, $\mathrm{pH}$, temperature and biological parameter like host specificity and wilting index. The obtained results showed that the optimal toxin-production conditions for $L$. theobromae in potato dextrose broth under $\mathrm{pH} 6.0$, at $25-35^{\circ} \mathrm{C}$ for 7 days. The liquid culture from all isolates were toxic to mango plants and induced the rapid wilting. The toxin obtained from the liquid culture has thermal, acid base stability and a broad range of toxicity to main host and non-host plants. Moreover, the direct bioassay for two components of the liquid filtrates precipitated by ethanol showed that the active ingredient of the toxin is a kind of non protein substance, which was further endorsed by the papain hydrolysis analysis. Our results confirmed the chemical nature of toxic compound elucidating the favorable environmental conditions for toxin production of $L$. theobromae and proved potential role of toxic metabolites in the mechanism of disease development.

Keywords: Bioassay, Lasiodiplodia theobromae, Partial characterization, Phytotoxin and Stem end rot

\section{INTRODUCTION}

Mango stem end rot caused by Lasiodiplodia theobromae impacted annual losses up to $70 \%$. Besides causing severe losses in the yield, the post-harvest diseases also reduce the quality of mango fruits (Awa et al., 2012). Lasiodiplodia theobromae (Pat.) Griffon and Maublis is a synonymous of Botryodiplodia theobromae. Sutton (1980) has adopted the name L. theobromae as suggested by Zambettakis (1954). B. theobromae (Pat.) is the anamorph stage of Botryosphaeria rhodina (Cooke) arx. The main features that distinguish this genus from other closely related genera are the presence of pycnidial paraphyses and longitudinal striations on mature conidia (Sutton, 1980; Sivanesan, 1984). Tovar-pedraza et al. (2012) observed that the pycnidium of L. theobromae was black, obpyriform and ostiolate. The symptom of stem end rot is tear-stain soft black lesions that run from the stem-end of the fruit to the basal end (Awa et al., 2012). He et al. (2004) found that the pathogen was isolated from the strip lesions formed within 24-48 h by puncture inoculation with mycelia, while quick necrotizing of mango was resulted from culture filtrates by leaf pin-pricking, which indicated that the toxin produced by the pathogen may play an important role in the pathogenesis of mango stem-end rot disease. Toxic metabolites produced by plant pathogenic microbes have long been demonstrated as virulence factor in many plant-pathogen interaction (Jeong et al., 2003). Extraction of toxin from virulent pathogens during infection and its biological investigation is an important criterion to prove the involvement of toxin in pathogenesis and disease development. However, toxin production by pathogens is influenced by their respective host, virulence of the pathogen, its cultural characters, nutrient status of both culture medium and environmental factors. In order to realize the biology and pathogenecity of the L. theobromae pathogen on the mango fruits and disclose the relationships among the toxin and pathogenicity. Physical and biological characteristics, nature of compound and action of the toxin produced from the liquid culture were inquired in detail in this paper.

\section{MATERIALS AND METHODS}

Pathogen: Ten single spore isolates of L. theobromae isolated from diseased mango fruits from different agro climate zones of Tamil Nadu state, India, namely Lt-1, Lt-2, Lt-3, Lt-4, Lt-5, Lt -6, Lt-7, Lt-8, Lt-9 and Lt-10 were used for the prelude experiments, while the isolate Lt-2 was used for all the other experimental procedures. At the mean time, all the collected isolates were asserted on yeast extract agar medium in $4^{\circ} \mathrm{C}$ refrigerator and changed new medium for each half a year. Potato dextrose agar medium was used for the pathogen growth. 
Vegetal material: Healthy mango leaves and fruits were collected freshly from Tamil Nadu Agricultural University experimental orchard and other non-host plants used in the host specificity experiments were grown in the glasshouse under natural light conditions at $25 \pm 2{ }^{\circ} \mathrm{C}$ with a relative humidity of $60-80 \%$. Before planting in a sterile mixture of soil, seeds were surface sterilized with $1 \%$ sodium hypochlorite followed by rinsing with sterile distilled water. When the fourth true leaves were fully expanded, the seedlings or detached young leaves were used to test the toxic activity of the culture filtrates.

Separation of crude filtrate: The Potato Dextrose Broth (PDB) distributed in $150 \mathrm{ml}$ aliquots was put in the $250 \mathrm{ml}$ Erlenmeyer flasks, and each flask was inoculated with single mycelial discs, $10 \mathrm{~mm}$ in diameter, taken from 7 day old culture of $L$. theobromae grown on potato dextrose agar at $26^{\circ} \mathrm{C}$. Unless otherwise declared, the cultures were incubated in the PDB at $26^{\circ} \mathrm{C}$ under normal day and night light regimes as static conditions and gently shaken by hand once half a day. Cultures from individual flasks were harvested after incubation for 7 days by filtering by using two layers of sterilized gauze and Whatman no. 1 filter paper, respectively. The culture filtrates without inert spores and mycelia were checked by the optical microscopy. The collected culture filtrate was stored at $2^{\circ}$ $\mathrm{C}$ until required and used as the source of toxins (Girish et al., 2009).

\section{Inoculation and toxic assay}

Leaves puncture inoculation: Needlepoint injuries were did on either side of each detached leaf, and 0.02 $\mathrm{ml}$ droplets of the toxic culture filtrate was applied to these wounds. Subsequently, these treated leaves were incubated for $72 \mathrm{hrs}$ at room temperature under 100\% RH in trays lined with moist blotting papers. At the end of the incubation period, the inoculated drops were removed by using a blotting paper, and the infection degree was ranked by the size of the lesions (Naik et al., 1991).

Root dipping inoculation: Nine different seedlings were dipped into the toxin filtrate $(40 \mathrm{ml})$ for each treatment, and the control plants were simultaneously incubated with filtrates from uninoculated broth. The symptoms of plants were assured on the $1^{\text {st }}$ to $5^{\text {th }}$ day after incubation, and each experiment was repeated thrice (Venkadaravannapa et al., 2007). The measures for classifying the symptoms of the tested seedlings are the same as that described previously. The disease severity was evaluated by calculating the wilting index.

Effect of osmotic potential on toxicity of the filtrate: Sucrose solutions of different osmotic potentials with one, two, four, and eight times that of the original culture filtrate $(131 \mathrm{kPa})$ were prepared by the ideal gas law $P V=n R T$, where $P$ is the potential in pascal, $V$ is the volume in cubic meters, $n$ is the number of moles of gas, $R$ is the universal gas constant, and $T$ is the temperature (Zhang et al., 2012). Then the effect of osmotic potential on the toxic activity of the culture filtrate was inquired by bioassay.
Effect of filtrate concentration on toxicity: The toxic culture filtrate was diluted by 1:2 proportion and the mango leaves were treated with the toxin filtrates in different concentrations.

Effect of culture conditions on toxin production Effect of culture broth $\mathrm{pH}$ on toxin production and its stability: The $\mathrm{pH}$ of culture broth was adjusted to 2.0, 4.0, 6.0, 7.0, 8.0 and 10.0 respectively, with $\mathrm{NaOH} / \mathrm{HCl}$. The toxic activity was examined by bioassay.

Effect of culture broth temperature on toxin production: The inoculated culture broth were incubated at different gradient temperatures 5, 10, 15, 20, 25, 30, 35,40 and $45^{\circ} \mathrm{C}$, respectively, and the toxic activity was bio assayed.

Time course of toxin production: To investigate the variation of toxin production at $25^{\circ} \mathrm{C}$ with time, the isolate Lt- 2 was used in the experiment, and the culture filtrates were harvested at 2 day intervals. The crude toxin was extracted and bio assayed as described previously.

Effect of pH on toxin stability: The $\mathrm{pH}$ of toxic filtrate (7.4) was adjusted to 4.0, 6.0 and 9.0, respectively, with $\mathrm{HCl} / \mathrm{NaOH}$, and thereafter, the toxic activity was bio assayed. Mean while control plants were inoculated with sterile distilled water of the corresponding $\mathrm{pH}$ adjusted by $\mathrm{HCl} / \mathrm{NaOH}$.

Effect of temperature on toxin stability: The toxic culture filtrate was incubated at 70 and $121^{\circ} \mathrm{C}$ for 10 , 20 and $30 \mathrm{~min}$, respectively, and thereafter, the toxic activity was bio-assayed by root dipping inoculation using mango seedlings of cultivar line Neelum.

Host specificity assay: The activity of the crude toxin of the isolate Lt-2 was examined by the root-dipping or detached leaf puncture inoculation on the non-host plants Boerhaavia diffusa (Nyctaginaceae), Capsicum annum (Solanaceae), Euphorbia geniculata (Euphorbiaceae), Euphorbia hirta (Euphorbiaceae), Nicotiana tobaccum (Solanaceae), Parthenium hysterophorus (Asteraceae), Phyllanthus niruri (Phyllanthaceae), Solanum lycopersici (Solanaceae) and Tridax procumbens (Asteraceae) (Parthasarathy et al., 2015).

Partial purification of the toxin and its activity: Liquid cultures of the L. theobromae isolate Lt-2 were harvested on the $7^{\text {th }}$ day of incubation. The filtrate was treated with three times volumes of ethanol and then centrifuged with $12,000 \times \mathrm{g}$ at $4^{\circ} \mathrm{C}$ for $20 \mathrm{~min}$ to precipitate the protein, polysaccharide and nucleic acids. The pellet was resuspended aseptically in sterilized distilled water with the same volume of original culture filtrate. The supernatant was treated in a rotary vacuum evaporator (Equitron Roteva, Medica instrument manufacturing company, Mumbai, India) at $50^{\circ} \mathrm{C}$ to exclude ethanol, and thereafter, sterile distilled water was added in order to restore the original volume of the supernatant. The toxic activity of the obtained pellet and supernatant was further bio analyzed with root dipping and detached leaf puncture inoculation, respectively using mango seedlings. The papain and cul- 
ture filtrate mixture was prepared by adding papain to the original culture filtrate at the final concentration of $0,0.2,0.4,0.6,0.8,1.0,2.5$ and $3.0 \mathrm{mg} / \mathrm{ml}$, respectively, and then treated in water bath at $37^{\circ} \mathrm{C}$ for $6 \mathrm{~h}$. The sterile distilled water added with papain was served as control (Zhang et al., 2012). The consequence of papain on the toxicity was inquired by root dipping inoculation.

\section{RESULTS AND DISCUSSION}

The Necrotrophic fungal genus Lasiodiplodia, belonging to Dothideomycetes, are important fungi causing economically significant diseases including spots, rots, and canker (Latha et al., 2012; Phipps and Porter, 1998; Tovar-pedraza et al., 2012), and toxin produced by Lasiodiplodia plays an important role in plant pathogenesis (He et al., 2004). The symptomatology, pathogenicity, cultural morphology and epidemiology of the mango stem end rot disease was investigated in 1940s and the pathogen was identified to belong to the genus Lasiodiplodia (Das gupta and Zachariah, 1945), but the species of $L$. theobromae had not been confirmed until 1992 (Narasimhudu and Reddy, 1992). As for the pathogenesis of the disease caused by L. theobromae, it remains unknown for a long time. Johnson et al. (1992) investigated the quiescent formation and infection capacity of the pathogen. Subsequently, the culture filtrates from pathogen of mango stem end rot disease also found to cause wilting symptom in mango, and the toxin-producing conditions were primarily investigated. This study dealt with the preliminary extraction and purification, characteristics, and activity of the toxin from liquid culture of $L$. theobromae, which might be helpful for further study and understanding the pathogenicity of L. theobromae. Environmental factors are typically highly variable and the heterogeneity is caused by variation in deposition of toxins in several fungi. Various factors comprising the internal or external environment may affect either the amount of toxins or their activity (Boonyapranai et al., 2008).

Toxic activity of the culture filtrates to mango: The filtered broth solution was directly applied to the mango leaves and fruits by pin pricking, and the ability of each strain of $L$. theobromae to induce necrotizing was measured. The mango leaves treated with culture filtrates could produce the typical necrotic patches symptoms of $L$. theobromae on the mango fruits. The mango leaves which was treated by culture filtrate for 12, 24 and 50 hrs showed light, moderate and severe wilting symptoms, respectively. This study proved the earlier work, that $L$. theobromae also caused some damages to the plants by producing toxins, like other species of Lasiodiplodia (He et al., 2004; Mario et al., 2012). In seedling bioassay, water soaked lesions appeared at the base of the stem in $24 \mathrm{hrs}$ and then spread to upwards, and the leaves withered, drooped, and crinkled. Then the wilting mango seedlings were transplanted into sterile distilled water, and after 24 hrs, they could not get back and the base of the stem turned brown. When the seedling was injected with the culture filtrate at the base of the stem, the dark brown stripe seemed on the stem after $24 \mathrm{hrs}$; subsequently, the plant dried up laterally. The results indicated that the culture liquid from all the eight strains of $L$. theobromae had an obvious effect on the mango leaves and fruits. Moreover, the culture filtrates of the strains caused the wilting effects with different degrees on the non host seedlings. The culture filtrates of the strains Lt-2, Lt-1, Lt-9 and Lt-5 had the stronger effect on the mango seedling and their corresponding wilting indexes were 96.12, 93.71, 91.68 and 89.32, respectively, and those of the strains Lt-10, Lt-6, Lt- 8 and Lt-4 caused the medium degree of wilt, the wilting indexes of which were 77.24, 72.10, 68.96 and 64.26, respectively, while the wilting indexes of those of the strains Lt-3 and Lt-7 were 52.61 and 48.17, respectively, showing lower toxicity (Table 1). Similar results were also obtained earlier, when $C$. gloeosporioides toxin treated on seedlings and mature leaves of mango (Jayasankar et al., 1999; Venkadaravannapa et al., 2007).

Effect of the osmotic potential on the toxic activity: Sucrose solutions of serial osmotic potentials did not cause any typical symptoms of the culture filtrate on the mango seedling but presented the osmotic injury at the late stage of the mango seedling. The leaves and stem of the mango plants damaged by osmotic stress did not cause the strip water soaked but dehydrated, and this symptom continued for several days, while the plants damaged by the toxic culture filtrate rapidly withered and the wilting index reached to 92.0 in the third day of cultivation (Fig. 1). Earlier, osmotic potential of $C$. capsici f. nicotianae toxin was also reported (Zhang et al., 2012).

Effect of concentration of the filtrate on toxicity: The toxic activity of the culture filtrate decreased with the increase of dilution degree. When diluted to $1 / 32$, the filtrate almost lost the toxicity (Fig. 2). In earlier study, we found that differentially diluted toxin of $C$. gloeosporioides cause merely similar kind of symptom on all the treated leaves (Parthasarathy et al., 2015), indicating that the least concentration of the toxin is necessary for its toxicity.

Effect of culture conditions on toxin production: The $\mathrm{pH}$ in the culture medium (6.0) is optimal for toxin production, and high or low $\mathrm{pH}$ conditions decrease the toxin production (Fig. 3). Similar observations have also been recorded by many earlier workers. The optimum $\mathrm{pH}$ for the growth and toxin production of Fusarium solani was found to be 6.0 by Merlin et al. (2013). Likewise maximum toxic metabolite production was obtained at $\mathrm{pH} 5.5$ from the strain Aspergillus terreus KC588297 (Mathan et al., 2013). Boonyapranai et al. 2008 obtained highest biomass yield and secondary metabolite production from Fusarium verticillioides at $\mathrm{pH} 5.0$ which decreased up to $\mathrm{pH} 10$ and 11. On the basis of present investigation $\mathrm{pH}$ 6.0 was selected for further investigation. 
Table 1. Effect of $L$. theobromae culture filtrates on mango seedlings.

\begin{tabular}{ll}
\hline Treatments & Wilting index (7 DAI) \\
\hline Lt-1 & 93.71 \\
Lt-2 & 96.12 \\
Lt-3 & 52.61 \\
Lt-4 & 64.26 \\
Lt-5 & 89.32 \\
Lt-6 & 72.10 \\
Lt-7 & 48.17 \\
Lt-8 & 68.96 \\
Lt-9 & 91.68 \\
Lt-10 & 77.24 \\
\hline
\end{tabular}

Table 2. Acidity-alkalinity stability of $L$. theobromae toxin.

\begin{tabular}{lllll}
\hline Treatments & \multicolumn{4}{l}{ Wilting index investigated at different } \\
& $\begin{array}{l}\text { time } \\
\mathbf{1}^{\text {st }} \mathbf{d a y}\end{array}$ & $\mathbf{2}^{\text {nd }} \mathbf{d a y}$ & $\mathbf{3}^{\text {rd }} \mathbf{d a y}$ & $\mathbf{4}^{\text {th }} \mathbf{d a y}$ \\
\hline $\begin{array}{l}\text { Crude filtrate } \\
\text { (pH 7.4) }\end{array}$ & 42.8 & 69.2 & 100 & 100 \\
$\begin{array}{l}\text { Filtrate (pH } \\
\text { 4.0) }\end{array}$ & 38.1 & 68.4 & 98.9 & 100 \\
Filtrate (pH & 36.4 & 71.5 & 100 & 100 \\
6.0) & & & & \\
Filtrate (pH & 28.7 & 58.3 & 98.6 & 100 \\
9.0) & & & & \\
Water (pH 4.0) & 0 & 0 & 0 & 0 \\
Water (pH 6.0) & 0 & 0 & 0 & 0 \\
Water (pH 9.0) & 0 & 0 & 0 & 0 \\
\hline
\end{tabular}

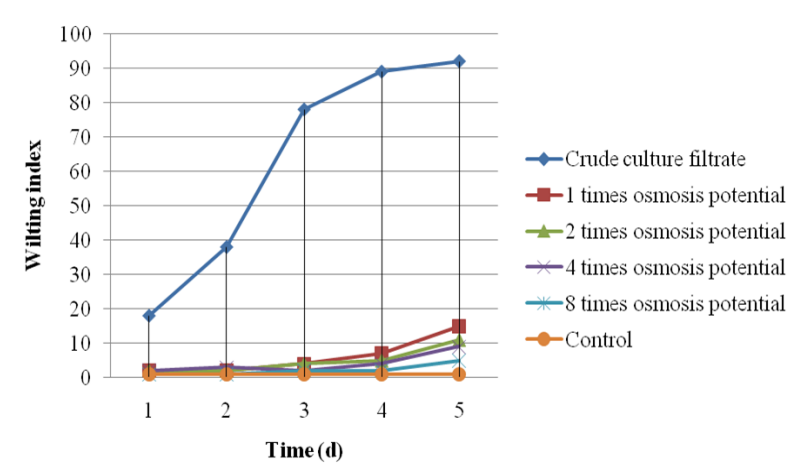

Fig. 1. Wilting index of mango seedlings by the toxic activity of the culture filtrates with serial osmotic potential in time (day).

Optimal temperatures are required for the production of any secondary metabolites by an organism. Therefore, the present investigation was carried out to determine the effect of temperature on toxic metabolite production by $L$. theobromae. As shown in fig. 4, the culture temperature has significant effect on toxin production of isolate Lt-2, and the optimal temperature is between 25 and $35^{\circ} \mathrm{C}$, at which the toxin production has significant difference with that at other temperatures, and the toxin productions are inhibited at the lower $\left(<15^{\circ} \mathrm{C}\right)$ and higher temperatures $\left(>40^{\circ} \mathrm{C}\right)$. Much lower as well as higher temperature failed to support toxic compound production. Variations in temperature requirement have also recorded by many workers. The temperature $25^{\circ} \mathrm{C}$ was reported as the optimum temperature for maximum bioactive metabolite production from Aspergillus terreus (Mathan et al., 2013). Toxin production by isolate Lt-2 was first detected at the third day after inoculation at $25^{\circ} \mathrm{C}$, and the toxicity increased with time and reached the maximum at the 13th day (Fig. 5).

Thermostable nature of crude toxin: The incubation temperature of crude toxin was up to $70^{\circ} \mathrm{C}$ for $30 \mathrm{~min}$ and $121^{\circ} \mathrm{C}$ for 10,20 and $30 \mathrm{~min}$, respectively. Toxicity of the original culture filtrate had almost lost when assessed using mango seedlings. The seedlings did not wither during the $1^{\text {st }}-4^{\text {th }}$ day after treated with the culture filtrates, and the wilting indexes were only up to $1.9,1.2,18.7$ and 16 respectively, at the $5^{\text {th }}$ day after treatment. When the temperature was up to $70^{\circ} \mathrm{C}$ for 10 and $20 \mathrm{~min}$, respectively, it caused a significant reduction of the toxicity during the $1^{\text {st }}$ to $3^{\text {rd }}$ day after treatment, but the toxin was not entirely destroyed and the toxicity nearly restored to the original statement before thermal treatment of the crude toxin at the $4^{\text {th }}$ and $5^{\text {th }}$ day (Fig. 6). The thermostabilty of toxins was also observed in Helminthosporium victoriae (Litzenberger, 1949) and C. capsici (Bhathagar and Kalpana, 1995). Thus the result clearly indicates the least possibility of inactivation of toxin of $L$. theobroamae in host tissues in nature due to atmospheric temperature.

Effect of $\mathbf{p H}$ on toxin stability: The toxin produced by $L$. theobromae remained stable at $\mathrm{pH} 4.0$ to 9.0 (Table 2). No significant difference appears among the toxicity of the culture filtrates with different acidityalkalinity, while the water control with corresponding acidity-alkalinity has no toxic activity on the mango seedlings.

Host specificity: The toxin produced by the isolate Lt2 caused 9 species of plants belonging to four families (Asteraceae, Euphorbiaceae, Nyctaginaceae and Solanaceae respectively) wilting. These plants showed different susceptibility to the culture filtrate, of which C. annum and N. tabacum of Solanaceae, B. diffusa of Nyctaginaceae and $P$. hysterophorus of Asteraceae were the most susceptive, causing the severest wilting symptoms; E. geniculata of Euphorbiaceae, E. geniculata of Euphorbiaceae and S. lycopersici of Solanaceae caused medium wilting symptoms or watersoaked, chlorotic lesions, while E. hirta of Euphorbiaceae only caused lighter wilting. The study clearly indicates that necrotrophic pathogen $L$. theobromae produces non host selective toxic metabolite. Sharma and Sharma (1966) noticed similar trend in an isolate of C. gloeosporioides, a causative of citrus die-back. Earlier, we proved the non host specificity of toxin produced by $C$. gloeosporioides a causative of mango anthracnose (Parthasarathy et al., 2015)

Preliminary purification of the toxin and its activity: Bioassay results showed that the toxic activity of the protein and non-protein components from the culture filtrate was significantly different. When the detached leaf was treated with the non-protein component, the puce oblong water soaked lesions appeared around the inoculation site and then expanded irregu- 


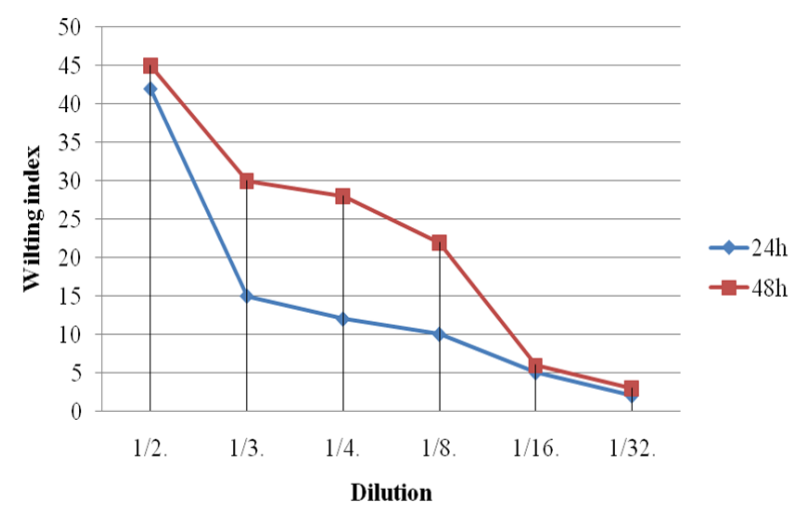

Fig. 2. Wilting index of mango seedlings by the toxic activity of the culture filtrates with serial concentrations after 24 and

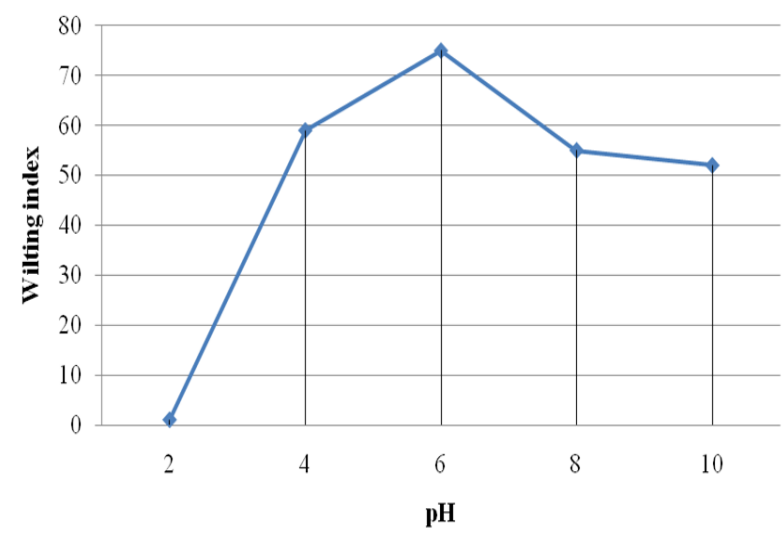

Fig. 3. $p H$ effect of culture medium on toxin production of $L$. theobromae.

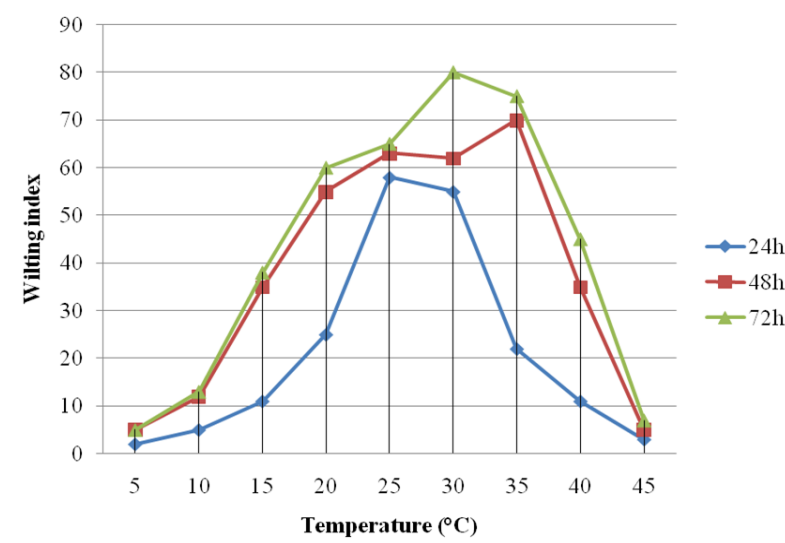

Fig. 4. Effect of culture temperature on toxin production of L. theobromae.

larly along with the vein, and the vein apart from the lesion also changed into brown. When the detached leaf was treated with the protein component, only the inoculation sites changed into yellow. In addition, as shown in fig. 7, the papain had no significant effect on the toxicity of $L$. theobromae toxin. Similar results were also found in detached leaf assay of protein and non-protein toxin fraction obtained from $C$. capsici f.sp. nicotianae (Zhang et al., 2012).

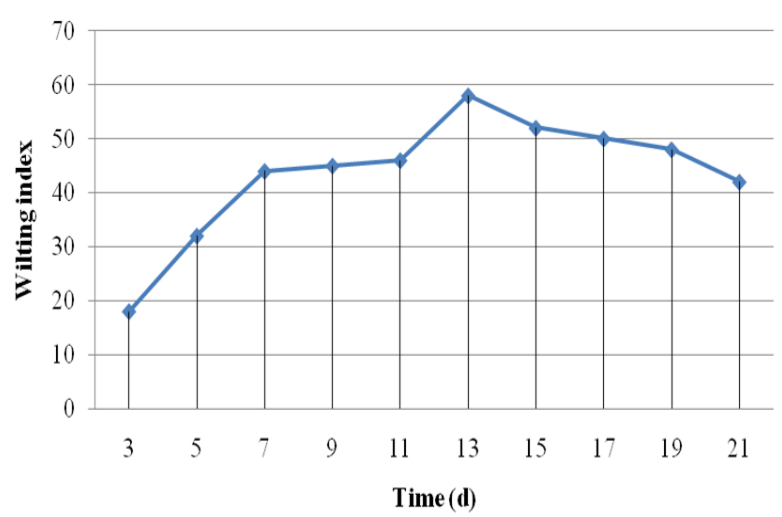

Fig. 5. Toxin production of L. theobromae with time in inoculation at $25^{\circ} \mathrm{C}$.

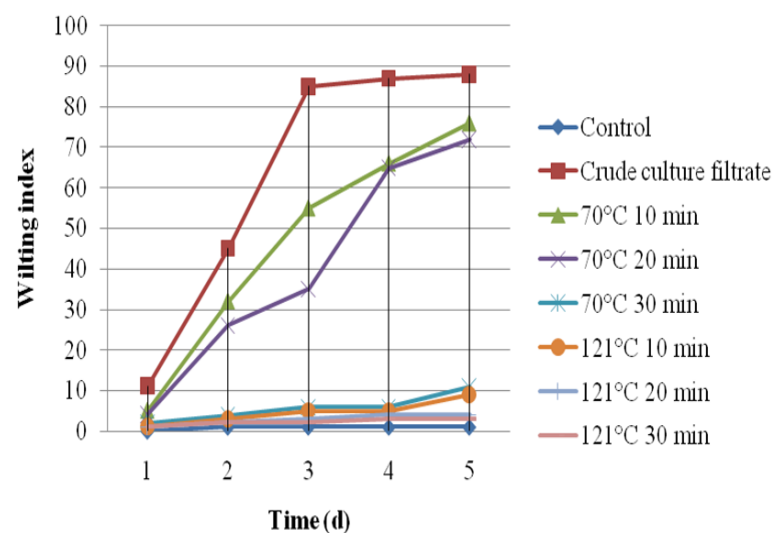

Fig. 6. Toxic activity of the toxin produced by L. theobromae when handled by two different temperatures.

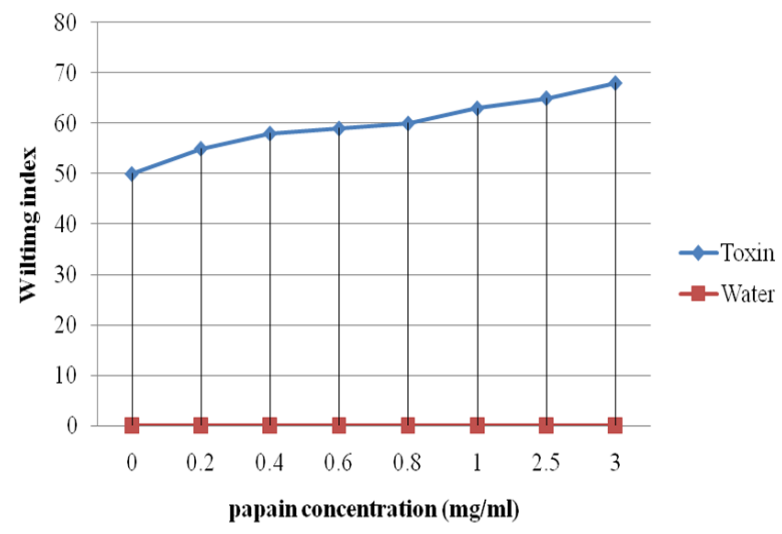

Fig. 7. Toxic activity of the toxin produced by L. theobromae when incubated with the papain.

\section{Conclusion}

The typical and irreversible symptoms of the mango seedlings treated with the culture filtrates suggested that the toxin was a pathological agent that caused the physiological changes on the host, and the action of the toxin produced by L. theobromae on the pathogenesis of the mango stem end rot disease was confirmed. Bioassay results of the culture liquid from eight strains of $L$. theobromae indicated that all the 
strains could produce the toxin in liquid culture, which caused wilting with different degree of severity on mango seedlings, and the culture filtrates causing strong wilting symptom were ineffective once diluted. The optimal toxin producing mode was under $\mathrm{pH} 6.0$ and 25 to $35^{\circ} \mathrm{C}$ for 13 days by vibrating in PDB medium. The toxin produced by $L$. theobromae has some stability to heat and acidity-alkalinity. This study also revealed the non-specific nature of the toxic metabolites from $L$. theobromae and the wide toxicity spectrum of the toxin, which was consistent with its host range. By ethanol precipitation, the toxin produced by L. theobromae was preliminarily purified, and this study showed that this toxin contained two components of the protein and non-protein. Bioassay of these two components showed that the active ingredient of the toxin is a kind of non-protein substances, and this was further confirmed by the papain hydrolysis test.

\section{ACKNOWLEDGEMENTS}

This work was carried out with the aid of a grant from the International Development Research Centre (IDRC), Ottawa, Canada, and with financial support from the Government of Canada, provided through Foreign Affairs, Trade and Development Canada (DFATD).

\section{REFERENCES}

Awa, O.C., Samuel, O., Oworu, O.O. and Sosanya, O. (2012). First report of fruit anthracnose in mango caused by Colletotrichum gloeosporioides in Southwestern Nigeria. Int. J. Sci. Tech. Res., 4 (1): 64-69.

Bhathagar, A. and Kalpana, S, (1995). Effect of certain carbohydrates on the pathogenesis of Colletotrichum capsici causing anthranose of chillies. Ind. Phytopathol., 24: $658-666$

Boonyapranai, K.B., Tungpradit, R., Lhieochaiphant, S. and Phutrakul, S. (2008). Optimization of submerged culture for the production of naphthoquinones pigment by Fusarium verticillioides. Chiang Mai J. Sci., 35 (3): 457-466.

Das gupta, S.N. and Zachariah, A.T. (1945). Dieback of mango. A new disease in India. Ind. J. Bot. Sci., 24 (1): 101-108.

Girish, K., Shnakara, B.S. and Raveesha, K.A. (2009). Crude toxin extract from culture filtrate of Phomopsis azadirachtae infecting neem and its phytotoxicity. Int. J. Integ. Biol., 6 (2): 79-84.

He, G., Matsuura, H. and Yoshihara, T. (2004). Isolation of $\alpha$ -methylene- $\gamma$-butyrolactone derivative, a toxin from the plant pathogen Lasiodiplodia theobromae. Phytochem., 65: 2803-2807.

Jayasankar, S., Litz, R.E., Gray, S. and Moon, P.A. (1999). Response of embryogenic mango cultures and seedling bioassays to a partially purified phytotoxin produced by a mango leaf isolate of Colletotrichum gloeosporioides Penz. In vitro Cell Dev. Biol. Plants., 35: 475-479.

Jeong, Y., Kim, J., Kim, S., Kang, Y., Nagamtsu, T. and Hwang, I. (2003). Taxoflovin produced by Burkholderia glumae causing rice grain rot responsible for inducing bacterial wilt in many filed crops. Plant Disease, 87: 890-895.

Johnson, G.I., Mead, A.J., Cooke, A.W. and Dean, J.R. (1992). Mango stem end rot pathogens - fruit infection by endophytic colonization of the inflorescence and pedicel. Ann. Appl. Biol., 120: 225-234.

Latha, P., Prakasam, V., Jonathan, E.I., Samiyappan, R. and Natarajan, C. (2012). Effect of culture media and environmental factors on mycelial growth and pycnidial production of Lasiodiplodia theobromae in physic nut (Jatropha curcus). J. Envi. Biol., 34: 683-687.

Litzenberger, S.C. (1949). Nature and susceptibility to Helminthosporium victoriae and resistance to Puccinia coronata in oats. Phytopathol., 39: 300-318.

Mario, A., Alves, D.C., Janaina, A.T., Raphael, C.I., Roney, R.B., Patricia, T.M., Avelina, A.I.F., Zuleica, B.F., Robert, F.H.P., Neelum, K. and Aneli, M.B. (2012). Lasiodiplodan, an exocellular (1-6)-b-D-glucan from Lasiodiplodia theobromae MMPI: production on glucose, fermentation kinetics, rheology and antiproliferative activity. J. Ind. Microb. Bio., 12: 1112-1127.

Mathan, S., Subramanian, V. and Nagamony, S. (2013). Optimization and antimicrobial metabolite production from endophytic fungi Aspergillus terreus KC 582297. Euro. J. Exp. Biol., 3 (4): 138-144.

Merlin, J.N., Nimal, I.V.S., Christhuda, S., Praveen, K.P. and Agastian, P. (2013). Optimization of growth and bioactive metabolite production: Fusarium solani. Asian J. Pharm. Clinical Res., 6 (3): 98-103.

Naik, K.S., Hiremath, P.C. and Hedge, R.K. (1991). Toxic metabolite production by Colletotrichum gloeosporioides causing blight of coriander. Karnataka J. Agri. Sci., 4: 27-31.

Narasimhudu, Y. and Reddy, P.S.N. (1992). A note on gummosis of mango. Ind. Phytopathol., 45 (2): 261-262.

Parthasarathy, S., Nagendran, K., Narayanan, P., Rajalakshmi, J., Thiribhuvanamala, G. and Prabakar, K. (2015). Novel insights into the phytotoxins production of Colletotrichum gloeosporioides causing anthracnose of mango. Trends Biosci., 8 (15): 3924-3927.

Phipps, P.M. and Porter, D.M. (1998). Collar rot of peanut caused by Lasiodiplodia theobromae. Plant Dis., 82: 1205-1209.

Sharma, M.C. and Sharma, B.C. (1966). Toxic metabolite production by Colletotrichum causing citrus die-back in India. Ind. Phytopathol., 22: 67-74.

Sivanesan, A. (1984). The bitunicate ascomycetes and their anamorphs. Cramer, Vaduz, 701pp.

Sutton, B.C. (1980). The Coelomycetes. Fungi imperfecti with pycnidia, acervuli and stromata. Commonwealth Mycological Institute, Kew, Surrey, U.K, 696pp.

Venkadaravannapa, V., Nargand, N.B., and Laxminarayanareddy, C.N. (2007). Variation in the toxic seconddary metabolite production by Colletotrichum gloeosporioides isolates causing mango anthracnose. J. Plant Prot. Envi., 4 (2): 34-40.

Tovar-pedraza, J.M., Mora-aguilera, J.A., Nava-diaz, C., Teliz-ortiz, D., Valdovinos-ponce, G., Villegas-monter, A. and Hernandz-morales, J. (2012). Identification, pathogenicity, and histopathology of Lasiodiplodia theobromae on mamey sapote grafts in Guerrero, Mexico. Agrocien., 46: 147-161.

Zambettakis, E.C. (1954). Recherrches sur la sytematique des "Sphaeropsidales -Phaeodidymae". Bull. Trimes. Soc. Mycol. Front., 70: 219-349.

Zhang, G.M., Fang, B.H., Chen, H. and Li, X.L. (2012). Characterisitcs of the toxin extracted from the liquid culture of Colletotrichum capsici f. nicotianae. App. Biochem. Biotech., 167 (52-61). 